\title{
The transformation of $\mathrm{Cu}(\mathrm{OH})_{2}$ into $\mathrm{CuO}$, revisited
}

\author{
Solid State Sciences, 5 (2003), 1471-1474
}

\begin{abstract}
Yannick Cudennec ${ }^{*}$, André Lecerf
Groupe de Recherche en Chimie et Métallurgie, Institut National des Sciences Appliquées de Rennes, 20 avenue des buttes de Coësmes, 35043 Rennes cedex, FRANCE.
\end{abstract}

\section{https://doi.org/10.1016/j. solidstatesciences.2003.09.009}

\begin{abstract}
Copper hydroxide $\mathrm{Cu}(\mathrm{OH})_{2}$ is metastable. It transforms easily into copper oxide $\mathrm{CuO}$ more stable, either in the solid state by a thermal dehydration or at room temperature, in aqueous basic solutions. In the solid state the transformation is performed at a relatively low temperature, $423 \mathrm{~K}$. It is a topotactic or a pseudo-morphic transformation for the reason that a clear relationship exists between axes of the two solids, in the three directions. The reacting process is described and corresponding vectorial relations between crystal parameters are proposed. It is not the same case in aqueous basic solutions. Copper hydroxide gives rise to oxide through the formation of a complex anion, $\mathrm{Cu}(\mathrm{OH})_{4}{ }^{2-}$, by a reconstructive transformation involving a dissolution reaction followed by a precipitation.
\end{abstract}

Key words : Copper hydroxide, copper oxide, topotactic, pseudo-morphic transformations.

* Author to whom correspondence must be send. Yannick.Cudennec@gmail.com 


\section{Introduction}

In previous publications, it has been shown that copper hydroxide $\mathrm{Cu}(\mathrm{OH})_{2}$ is a metastable phase which transforms easily into copper oxide $\mathrm{CuO}$, more stable [1-5]. That transformation occurs in solid state by thermal dehydration at a relatively low temperature, but exists also in aqueous media at room temperature. In 1970, Günter and Ostwald [5] published the results of studies about this question. Copper hydroxide was easily decomposed thermally or by electron irradiation, in an electronic microscope. Thermal decomposition of $\mathrm{Cu}(\mathrm{OH})_{2}$ in the range of 298 to $1273 \mathrm{~K}$ in air, was followed by means of a high temperature X-ray powder diffraction camera. At about $323 \mathrm{~K}$ a reversible increase of the c parameter of about $1.5 \%$ is observed and at $423 \mathrm{~K}$, the DTA curve is characterised by a large endothermic peak which corresponds to the dehydration of $\mathrm{Cu}(\mathrm{OH})_{2}$ and the formation of $\mathrm{CuO}$ [5]. Another transformation takes place at a higher temperature $(1093 \mathrm{~K})$, giving rise to $\mathrm{Cu}_{2} \mathrm{O}$, but that will not be the matter of this publication. Günter and Ostwald propose a hypothesis of a topotactic transformation between $\mathrm{Cu}(\mathrm{OH})_{2}$ and $\mathrm{CuO}$, which transforms only the a axis of the hydroxide into the $\left[\begin{array}{lll}1 & 1 & 0\end{array}\right]$ direction of $\mathrm{CuO}$. They think that topotactic reactions do not necessarily need a three-dimensional similarity between structures.

The aim of this publication is to propose an explanation for transformations of $\mathrm{Cu}(\mathrm{OH})_{2}$ which happen below $473 \mathrm{~K}$, a hypothesis of the process which gives rise to $\mathrm{CuO}$ from $\mathrm{Cu}(\mathrm{OH})_{2}$ in the solid state and compare it with reactions occuring in aqueous solutions at room temperature.

\section{Crystal structures of $\mathrm{Cu}(\mathrm{OH})_{2}$ and $\mathrm{CuO}$}

In order to understand the transformation on a crystallographical point of view, it is necessary to briefly describe the crystal structure of the two solids. 
The crystal structure of copper(II) hydroxide is orthorhombic, space group $\mathrm{Cmc} 2{ }_{1}\left(\mathrm{n}^{\circ} 36\right)$ with $\mathrm{a}(\AA)=2.9471, \mathrm{~b}(\AA)=10.593, \mathrm{c}(\AA)=5.2564(\AA), \mathrm{Z}=4$ [6]. It is related to lepidocrocite $\gamma-\mathrm{FeO}(\mathrm{OH})[4]$. The structure presents corrugated layers perpendicular to the $b$ axis, in which copper(II) has a pentahedral surrounding composed of five $\mathrm{OH}^{-}$ions ( $\mathrm{Cu}-\mathrm{O}: 1.95,1.95,1.97$, 1.97 and $2.36 \AA$ ). The sixth one is located at a too long distance ( $\mathrm{Cu}-\mathrm{O}: 2.92 \AA$ ) for being involved in the copper polyhedron (Fig. 1a). Copper atoms are located at about $0,13 \AA$ of the square basis built with oxygens.

As for the structure of $\mathrm{CuO}$, it was established in 1935 [7] and revisited in 1970 [8]. It is monoclinic, space group $\mathrm{C} 2 / \mathrm{c}\left(\mathrm{n}^{\circ} 15\right): \mathrm{a}(\AA)=4.6837, \mathrm{~b}(\AA)=3.4226, \mathrm{c}(\AA)=5.1288, \beta=$ $99.54^{\circ}, Z=4$. It is built of crossing bands of copper(II) with square planar surroundings $\mathrm{CuO}_{4}$, linked together by two opposite edges and spreading out in the directions $\left[\begin{array}{lll}1 & 1 & 0\end{array}\right]$ and [1 110$]$ (Fig. 1b). In all crystallized solids, divalent copper surroundings are always very distorted by a strong Jahn-Teller effect which often leads to square planar surroundings, more stable.

\section{Hypothesis of transformation processes in the solid state}

The structure of $\mathrm{Cu}(\mathrm{OH})_{2}$, in projection along the $\mathrm{A}$ axis is reported on the figure $2 \mathrm{a}$. Copper surrounding is pentahedral with four short $\mathrm{Cu}-\mathrm{O}$ bonds and a medium one at $2.36 \AA$. At about $323 \mathrm{~K}$, we think that a modification of surroundings of copper is performed, to give rise to square planar entities $\mathrm{Cu}(\mathrm{OH})_{4}$ linked together by two edges ( Fig.2b and 2c). This modification is reversible and could be responsible, with the thermal dilatation, of the weak increase of the $\mathrm{C}$ axis mentioned by Günter et al.[5]. Therefore, the stability of the structure is due to the network of hydrogen bonds. In fact, that structural conformation allows possibilities of easy shifts of $\mathrm{CuO}_{4}$ groups or $\mathrm{Cu}$ atoms which promote the evolution of $\mathrm{Cu}(\mathrm{OH})_{2}$ towards crystallized $\mathrm{CuO}$ at a low temperature. 
At the temperature of $423 \mathrm{~K}$, begins the dehydration of $\mathrm{Cu}(\mathrm{OH})_{2}$, characterised by a large endothermic DTA peak, according to the following scheme:

$$
\mathrm{Cu}(\mathrm{OH})_{2(\mathrm{~s})} \longrightarrow \mathrm{CuO}_{(\mathrm{s})}+\mathrm{H}_{2} \mathrm{O}_{(\mathrm{g})}
$$

The loss of water is performed by an oxolation mechanism [9], described on the figure 3 , giving rise to $\mathrm{O}-\mathrm{Cu}-\mathrm{O}$ bridges, between layers of $\mathrm{Cu}(\mathrm{OH})_{2}$.

The figure $3 \mathrm{a}$ corresponds to the $(\mathrm{A}, \mathrm{B})$ plane of the structure of $\mathrm{Cu}(\mathrm{OH})_{2}$. Layers of $\mathrm{Cu}(\mathrm{OH})_{2}$ are shifted of $\mathrm{A} / 2$ along $\mathrm{A}$, that explains why the $\mathrm{B}$ parameter corresponds to two interlayer spaces. The oxolation phenomenon involves a dehydration process and the formation of $\mathrm{O}$ $\mathrm{Cu}-\mathrm{O}$ bridges (see Fig $3 \mathrm{~b}$ and $3 \mathrm{c}$ ). Bridges are obtained after the loss of water molecules followed by a big contraction of the structure along the $\left[\begin{array}{lll}0 & 1 & 0\end{array}\right]$ direction (value near of $B / 2$ ). On the figure $3 \mathrm{~d}$ ( $\mathrm{B}, \mathrm{C}$ plane), is described the linkage of $\mathrm{CuO}_{4}$ entities along the $\mathrm{C}$ parameter, which produces a three-dimensional network. Half the rows of $\mathrm{CuO}_{4}$ bands are shifted along the $\left[\begin{array}{lll}0 & 1 & 0\end{array}\right]$ direction ( noted shift 1 on the figure $3 \mathrm{~d}$ ) of a value near $1.4 \AA$, in order to line up copper atoms along the $\mathrm{C}$ direction ( see figure $2 \mathrm{c}$ ). In addition, a second shift of half the copper atoms ( shift 2 of $\mathrm{C} / 4=1.3 \AA$ ), arises to put these copper atoms shifted, at equal distances of four oxygens belonging to four different $\mathrm{CuO}_{4}$ groups. Therefore, four $\mathrm{Cu}-\mathrm{O}$ bonds are established and the three-dimensional structure of $\mathrm{CuO}$ is obtained as it can be seen on the perspective view of the figure $3 \mathrm{e}$. Naturally, these different shifts are simultaneously performed during the oxolation process. They have been disconnected on the figures for a better understanding of the weak atom displacements.

Vectorial relations between crystal parameters of the structures of $\mathrm{Cu}(\mathrm{OH})_{2}$ and $\mathrm{CuO}$, corresponding to the proposed transformation, are reported in the table. As it can be seen, in these relations appears the relation between the directions $\left[\begin{array}{lll}1 & 0 & 0\end{array}\right]$ and $\left[\begin{array}{lll}1 & 1 & 0\end{array}\right]$ of the respective structures $\mathrm{Cu}(\mathrm{OH})_{2}$ and $\mathrm{CuO}$, mentioned by Günter et al.[5]. Nevertheless, contrarily to these 
authors, we propose a three-dimensional structural relationship, with relations between respectively [ $\left[\begin{array}{lll}0 & 0\end{array}\right]$ and [ $\left[\begin{array}{lll}1 & 1 & 0\end{array}\right]$ and also between [ $\left[\begin{array}{lll}0 & 1 & 0\end{array}\right]$ and [ $\left[\begin{array}{lll}0 & 0 & 1\end{array}\right]$.

\section{Transformation in aqueous solutions}

In previous publications [2],[3], we have shown that pure copper hydroxide can stay several months in pure water at room temperature, without being transformed in $\mathrm{CuO}$. Nevertheless, a slow transformation is thermodynamically possible because the solubility found in pure water is more important for $\mathrm{Cu}(\mathrm{OH})_{2}\left(1.310^{-5} \mathrm{~mol} . \mathrm{L}^{-1}\right)$ than for $\mathrm{CuO}\left(210^{-7} \mathrm{~mol} . \mathrm{L}^{-1}\right)$ [2]

It is quite different in presence of hydroxide ions $\mathrm{OH}^{-}$. Kinetic of transformation is very fast for the reason that divalent copper ions are dissolved into tetrahydroxocuprate(II) anions $\mathrm{Cu}(\mathrm{OH})_{4}{ }^{2-}$. In a previous publication [2], we have determined at room temperature, by means of an ICP spectrometer, the solubility of divalent copper in the system $\mathrm{Na}_{2} \mathrm{O}, \mathrm{CuO}, \mathrm{H}_{2} \mathrm{O}$. Concentrations of divalent copper in soda solutions are found around $10^{-3}$ mol. $\mathrm{L}^{-1}$ and can reach $6.10^{-2}$ mol. $\mathrm{L}^{-1}$ in very concentrated soda solutions. It is clear that copper concentrations can present such values only if copper is involved in a complex anion like $\mathrm{Cu}(\mathrm{OH})_{4}{ }^{2-}$, stabilized by the strong Jahn-Teller effect displayed by divalent copper, which leads to a square plane surrounding. This anion can be considered as a precursor entity for the formation of $\mathrm{CuO}$. In fact, a condensation phenomenon, combined with a loss of two hydroxyle ions and one water molecule, lead to the formation of chains of square plane $\mathrm{CuO}_{4}$ groups and then to the solid $\mathrm{CuO}$. Consequently, we think that the transformation of $\mathrm{Cu}(\mathrm{OH})_{2}$ into $\mathrm{CuO}$ more stable, in aqueous solution at room temperature, is a reconstructive transformation involving a dissolution reaction followed by precipitation and it is not a topotactic reaction [3]: 


$$
\begin{aligned}
\mathrm{Cu}(\mathrm{OH})_{2(\mathrm{~s})}+2 \mathrm{OH}_{(\mathrm{aq})} \longrightarrow \mathrm{Cu}(\mathrm{OH})_{4}{ }_{(\mathrm{aq})}^{2-} \\
\downarrow \\
\mathrm{CuO}_{(\mathrm{s})}+2 \mathrm{OH}_{(\mathrm{aq})}+\mathrm{H}_{2} \mathrm{O}
\end{aligned}
$$

Thanks to this process the fast transformation of $\mathrm{Cu}(\mathrm{OH})_{2}$ into $\mathrm{CuO}$ is possible at room temperature in soda solutions

\section{Conclusion}

Copper hydroxide $\mathrm{Cu}(\mathrm{OH})_{2}$ is metastable. That explains why it is difficult to obtained a pure solid phase. In a recent publication, we have shown that instability is mainly due to the peculiar surrounding of one oxygen atom which is composed of only two copper and one hydrogen, atoms (See Fig. 1a). The same feature is found in lepidocrocite $\gamma-\mathrm{FeO}(\mathrm{OH})$, which crystal structure is related to that of $\mathrm{Cu}(\mathrm{OH})_{2}$ and which is also a metastable phase compared to the stable goethite $\alpha-\mathrm{FeO}(\mathrm{OH})$ [4]. Contrarily to the hydroxide, in the oxide $\mathrm{CuO}$, oxygen surroundings are more stable. They are composed of four copper atoms ( See Fig. 1b). In fact, in the most stable hydroxides of brucite type, each oxygen is involved in a tetrahedral polyhedron built-up with three metal and one hydrogen atoms. Therefore it is not surprising if copper hydroxide decomposes at relatively low temperature in comparison with others divalent metal hydroxides of brucite type. In addition the shift of $\mathrm{A} / 2$ along $\mathrm{A}$ of layers in the structure of $\mathrm{Cu}(\mathrm{OH})_{2}$ (see fig.3a), favours the formation of $\mathrm{CuO}$ insofar as atom displacements are reduced. Therefore we think that this characteristic is also an instability factor.

If copper hydroxide decomposes at room temperature in aqueous soda solutions by a reconstructive transformation, nevertheless a structural relationship exists with $\mathrm{CuO}$. At a higher temperature it is evident that a transformation takes place within the solid phase. The 
main feature, common to the two transformations, performed either in solution or in the solid state, is the formation of square planar entities $\mathrm{CuO}_{4}$ which can be considered as the elementary bricks, giving rise to $\mathrm{CuO}$.

For Cornell and Schwertmann [10], a topotactic transformation involves internal atomic rearrangements with a single crystal of the initial phase, transforming into a single crystal of another phase. In addition, an agreement in three dimensions between the initial and the final structure must be obtained, contrarily to Günter and Ostwald [5] who think that one dimension is enough. Other solid state reactions in which the end product is not a single crystal but where nevertheless, there is a clear relationship between crystal axes of the two structures, could be termed as pseudo-morphic.

Thanks to Professor Gérard Ferey for his helpful and valuable comments about these transformation processes.

\section{References}

[1] Cudennec Y., Lecerf A., Riou A., Gérault Y., Eur. J. Solid State Inorg. Chem., 25 (1988) 351-358.

[2] Cudennec Y., Lecerf A., Gérault Y., Eur. J. Solid State Inorg. Chem., 32 (1995) 10131022.

[3] Cudennec Y., Riou A., Lecerf A., Gérault Y., C. R. Acad. Sci. Paris, Série Ilc 3 (2000) 661-666.

[4] Cudennec Y., Lecerf A., C. R. Acad. Sci. Paris, Chemistry 4 (2001) 885-891.

[5] Günter J.R., Ostwald H.R., J. Appl. Cryst., 3 (1970) 21-26.

[6] Ostwald H.R., Reller A., Schmalle H.W., Dubler E., Acta Cryst., C46 (1990) 2279-2284.

[7] Tunell G., Posnjak E., Ksanda C.J., Z. Kristallogr., 90 (1935) 120. 
[8] Åsbrink S., Norrby L.J., Acta Crystallogr., B26 (1970) 8-15.

[9] Jolivet J.P., De la solution à l'oxyde, Savoirs actuels Interéditions/CNRS, (Nov.1994) 112167.

[10) Cornell R.M., Schwertmann U., The iron oxides; structures; properties; reactions; occurrences and uses (1996) V.C.H., Weinheim. 
Table : Vectorial relations between axes

\begin{tabular}{|c|c|c|c|}
\hline $\mathrm{Cu}(\mathrm{OH})_{2} \mathrm{Cmc}_{2}$ & $\mathrm{CuO} \mathrm{C} 2 / \mathrm{c}$ & Relations between axes & Comments \\
\hline $\mathrm{A}=2.9471 \AA$ & $\mathrm{a}=4.6837 \AA$ & $\overrightarrow{\mathrm{A}} \Leftrightarrow \frac{\overrightarrow{\mathrm{a}}-\overrightarrow{\mathrm{b}}}{2}(2.90 \AA)$ & $\begin{array}{l}\text { As expected, a weak variation is } \\
\text { observed along this direction. } \\
\text { (distance between copper of } 2 \\
\text { neighbouring square planar } \\
\text { surroundings ) }\end{array}$ \\
\hline $\mathrm{B}=10.593 \AA$ & $\mathrm{b}=3.4226 \AA$ & $\overrightarrow{\mathrm{B}} \Leftrightarrow \overrightarrow{\mathrm{c}} \quad(5.1288 \AA)$ & $\begin{array}{l}\text { Big contraction of the structure } \\
\text { due to the loss of water. }\end{array}$ \\
\hline $\mathrm{C}=5.2564 \AA$ & $c=5.1288 \AA$ & $\overrightarrow{\mathrm{c}} \Leftrightarrow \overrightarrow{\mathrm{a}}+\overrightarrow{\mathrm{b}}(5.80 \AA)$ & $\begin{array}{l}\text { Small increase due to the shift of } \\
\mathrm{C} / 4 \text { of half the copper atoms. }\end{array}$ \\
\hline l & $\beta=99.54^{\circ}$ & & \\
\hline
\end{tabular}




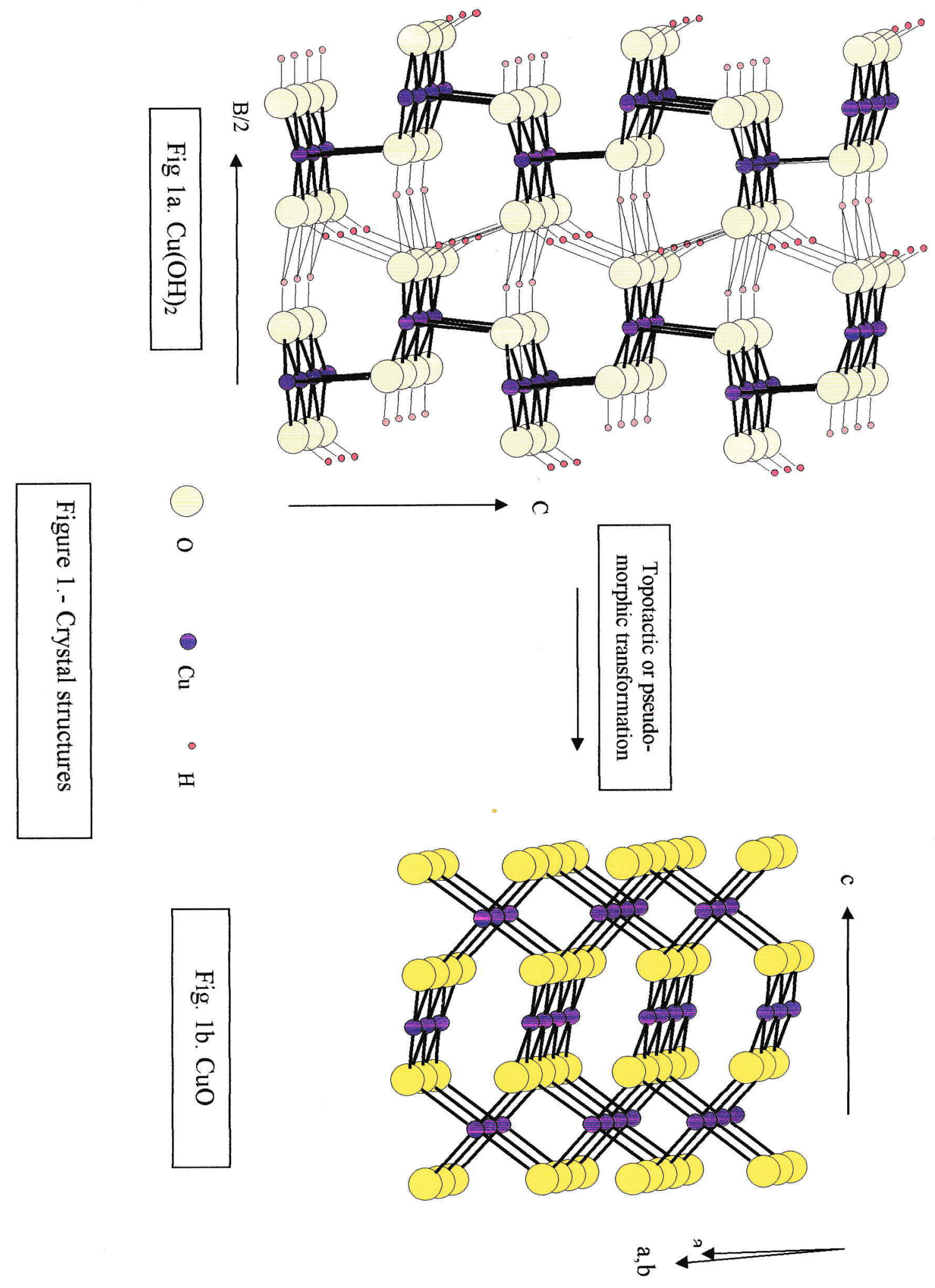



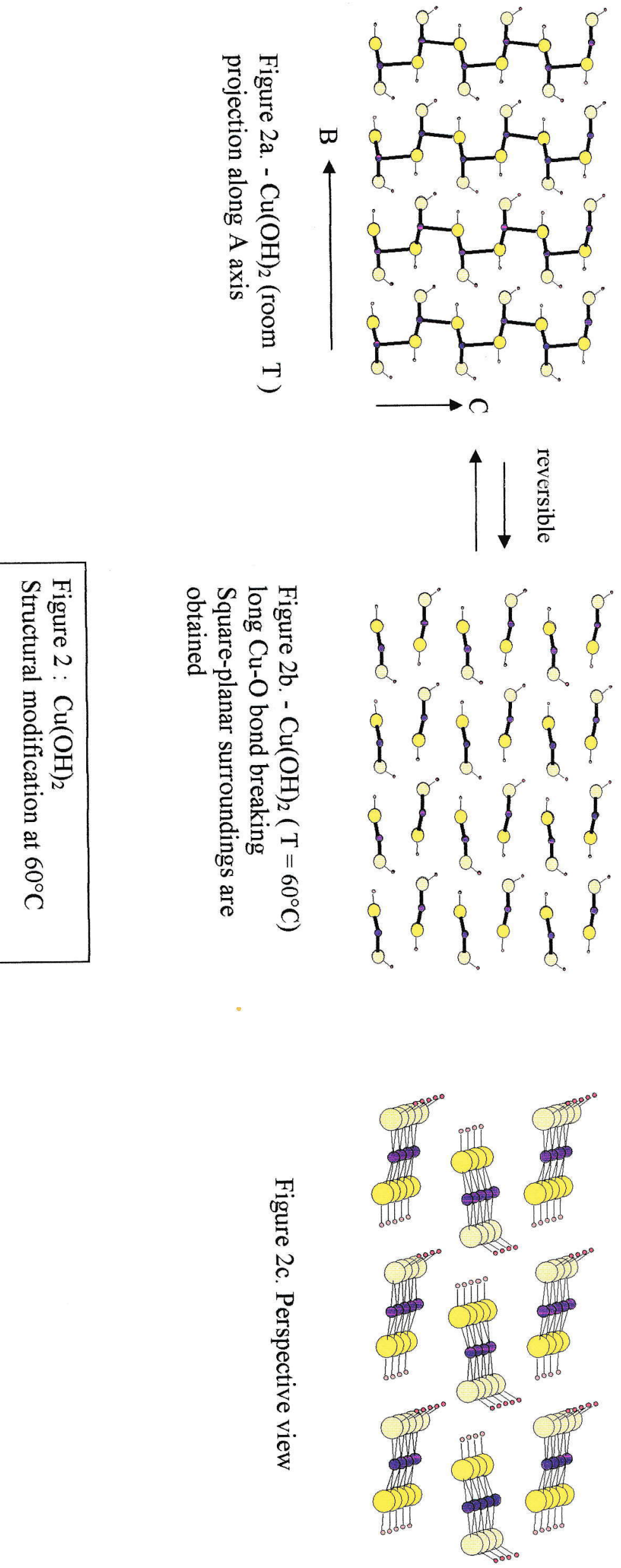

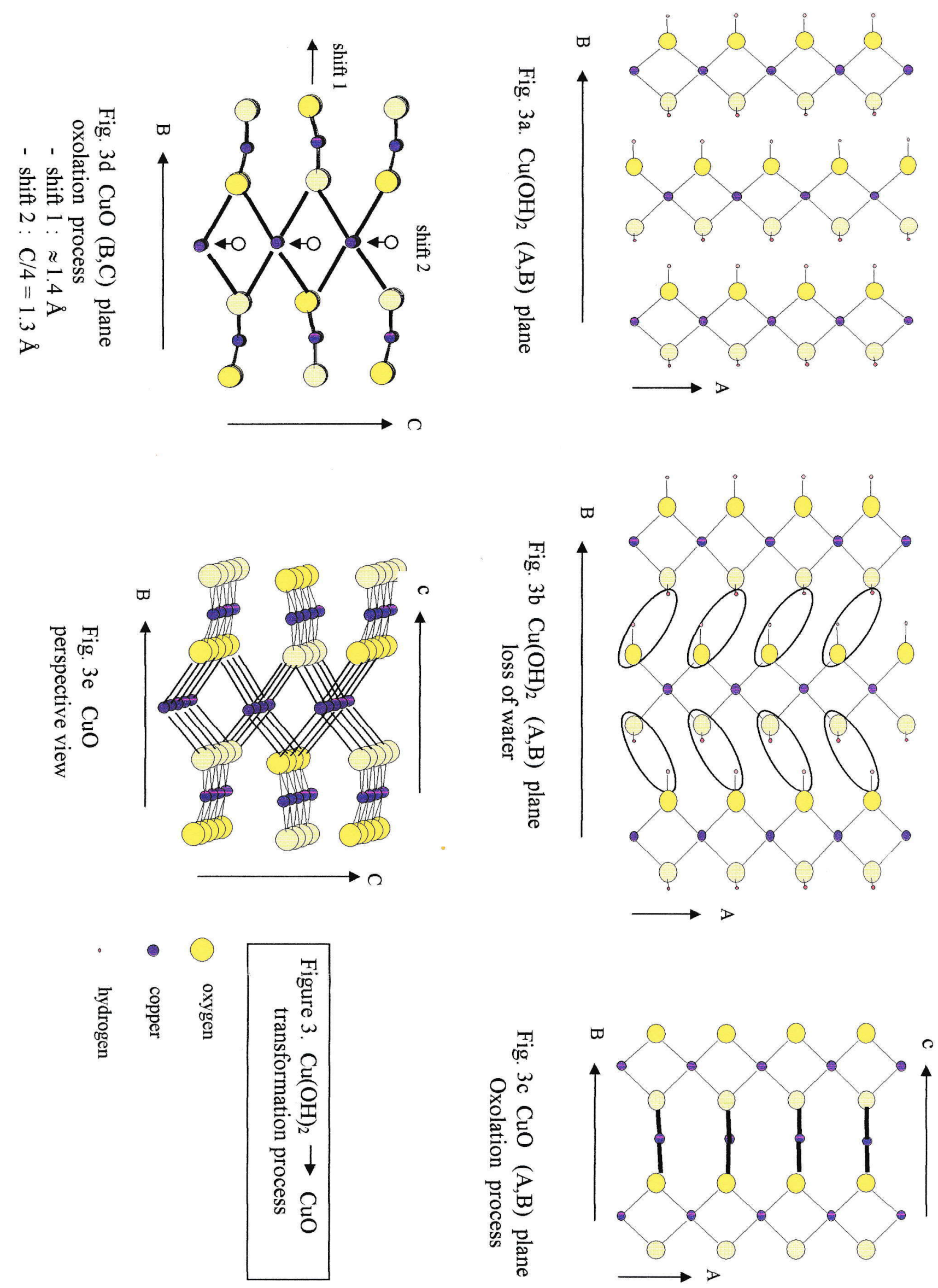